\title{
Microwave-Assisted Oxidation of Organic Compounds with Cetyltrimethylammonium Chlorochromate
}

\author{
Mohammd Kazem Mohammadi \\ Faculty of Science, Ahvaz Branch, Islamic Azad University, Ahvaz, Iran \\ Email: mkmohamadi@yahoo.com
}

Received November 9, 2012; revised May 11, 2013; accepted June 2, 2013

Copyright (C) 2013 Mohammd Kazem Mohammadi. This is an open access article distributed under the Creative Commons Attribution License, which permits unrestricted use, distribution, and reproduction in any medium, provided the original work is properly cited.

\begin{abstract}
An efficient and mild methodology for oxidation of organic compounds is described using Cetyltrimethylammonium Chlorochromate (CTMACC) under microwave irradiation. The reactions are performed cleanly and are controlled to stop at aldehyde stage, without over-oxidation and side products. Oxidation of organic compounds to their corresponding carbonyl compouds, are studied under microwave radiation. The easy procedure, simple workup, short reaction times, and excellent yields, are another advantages of this reagent.
\end{abstract}

Keywords: Oxidation; Organic Compounds; Chlorochromate; Microwave Irradiation

\section{Introduction}

Microwave-assisted organic synthesis (MAOS) is a new and quickly developing area in synthetic organic chemistry.

This synthetic technique has been based on the empirical observation that some organic reactions proceed much faster and with higher yields under microwave irradiation compared to conventional heating. In many cases reactions that normally require many hours at reflux temperature under classical conditions can be completed within several minutes or even seconds in a microwave oven, even at comparable reaction temperatures. While different hypotheses have been proposed to account for the effect of microwaves on organic reactions, the reason for such dramatic acceleration effects remains largely unknown. Regardless of the exact origin of the microwave effect, it is extremely efficient and applicable to a very broad range of practical syntheses.

The oxidation of alcohols to carbonyl compounds is a fundamental transformation in organic chemistry since carbonyl compounds are widely used as intermediates both in manufacturing and research [1]. Although the oxidation of organic compounds under non-aqueous conditions has become an effective technique for modern organic synthesis [2], the methods still suffer some disadvantages including the cost of preparation, long reaction time, and tedious work-up procedures. In recent years, oxidation processes have received much attention, especially in the search for selective and environmentally friendly oxidants [3-8].

Microwave synthesis is a new technique for conducting chemical reactions. Acceleration of organic reactions by microwaves has been largely proven elsewhere, and in many cases, microwave techniques have become more effective than conventionally conducted reactions [9-12].

Moreover, in a number of applications, reactions under microwave conditions can provide pure products in high yield [13-15].

Recently, using reactants adsorbed on inorganic supports and microwave activation, Varma et al. [16-20] have published several examples of oxidation reactions of alcohols to carbonyl compounds as well as sulfides to sulfoxides and sulfones. Under similar conditions $\left(\mathrm{KMnO}_{4}\right.$ adsorbed on alumina), Loupy et al. [21] have converted aromatic hydrocarbons to aromatic ketones; whereas Palombi et al. [22] reported alcohols oxididation using t-butyl hydroperoxide supported on zeolites. In the present paper we report a fast and facile microwave accelerated oxidation of primary alcohols to aldehydes and secondary alcohols to ketones. The Oxidation reactions of some alcohols and pol yarenes by CTMABC using conventional method have been reported earlier by us [23].

\section{Experimental}

\subsection{Material and Methods}

$\mathrm{CrO}_{3}$ (Merck, P.A.) was used without further purification. 
Solvents were purified by standard methods. Chrommium, was estimated iodometrically. In the case of the reduced product of the oxidant, chromium was determined after oxidizing with acidic peroxodisulfate $\left(\mathrm{K}_{2} \mathrm{~S}_{2} \mathrm{O}_{8}\right)$ solution. Melting points are measured on an Electrothermal 9100 melting point apparatus.

Experiments were carried out in closed vessel multi mode Microsynth Milstone laboratory microwave oven using a 900 Watts WestPoint microwave operating at $3.67 \mathrm{GHz}$ with an internal volume of $0.9 \mathrm{~m}$. All experiments had good reproducibility by repeat the experiments in same conditions.

\subsection{General Procedure for Synthesis of CTMABC}

Cetyltrimethylammonium Bromochromate (CTMABC) was prepared by the reported method (Scheme 1) [23].

$\mathrm{C}_{19} \mathrm{H}_{42} \mathrm{BrCrNO}_{3}$ : calc. C, 49.14; $\mathrm{H}, 9.05 ; \mathrm{N}, 3.01$. Found: C, 48.76; H, 9.19; N, 2.95. ${ }^{1} \mathrm{H} \mathrm{NMR}\left(\mathrm{CDCl}_{3}\right)$ : d $3.31(\mathrm{~s}, 9 \mathrm{H}), 3.25(\mathrm{t}, 2 \mathrm{H}), 1.73(\mathrm{t}, 2 \mathrm{H}), 1.30(\mathrm{~s}, 26 \mathrm{H})$, $95(\mathrm{t}, 3 \mathrm{H})$.

IR $(\mathrm{KBr}): 904 \mathrm{~cm}^{-1} v_{1}\left(\mathrm{~A}_{1}\right)$ or $v\left(\mathrm{CrO}_{3}\right), 394 \mathrm{~cm}^{-1} v_{2}$ $\left(\mathrm{A}_{1}\right)$ or $v(\mathrm{Cr}-\mathrm{Br}), 940 \mathrm{~cm}^{-1} v_{4}(\mathrm{E})$ or $v\left(\mathrm{CrO}_{3}\right) \mathrm{cm}^{-1}$.

This procedure can be performed on a $250-\mathrm{g}$ scale without any difficulty.

\subsection{General Procedure for Oxidation of Alcohols and Polyarenes under Microwave Irradiation}

In a small-scale experiment CTMABC (1 mmol) was suspended in dichloromethane (ca. $2 \mathrm{ml}$ ) and an alcohol ( $1 \mathrm{mmol}$ in 0.5 to $1.5 \mathrm{ml}$ of $\mathrm{CH}_{2} \mathrm{Cl}_{2}$ ) was rapidly added at room temperature and the resulting mixture stirred vigorously for the appropriate time. The mixture was irradiated for the time indicated in the table by microwave radiation (3.67 GHZ, $300 \mathrm{~W}$ ) (Table 1). The molar ratio of substrate to oxidant was 1:1 in the case of alcohols and 1:2 in the case of polycyclic arenes (antracene and phenantrene). The solution became homogeneous briefly before the black-brown reduced reagent precipitated. The progresses of the reactions were monitored by TLC and UV/Visible spectrophotometr (at $352 \mathrm{~nm}$ ). Analysis of the reaction mixture for the corresponding carbonyl compound was accomplished by the procedure reported

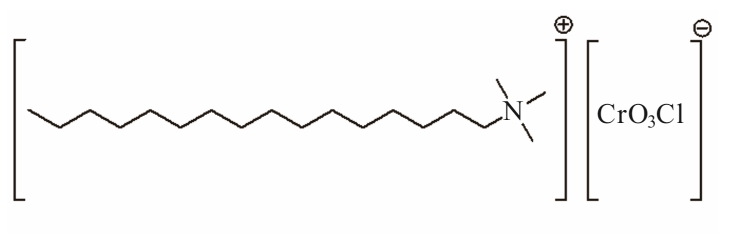

Cetyltrimethylammonium Chlorochromate (CTMACC)

Scheme 1. Cetyltrimethylammonium Chloromochromate (CTMACC). in earlier papers. All products were known and determined with melting point comparison with the published manuscript [23-25]. The above procedure may be carried out on $1-100 \mathrm{~g}$ scales without any problem.

\section{Results}

In this paper, CTMABC was used for the oxidation of some alcohols and polycyclic arenes under microwave irradiation in $\mathrm{CH}_{2} \mathrm{Cl}_{2}$ as solvent. This method offers some advantages in term of simplicity of performance, simple operation condition, no side product formation, very low reaction time and a wide range of substrates can be converted to their corresponding aldehydes and ketones. In addition, the reduced reagent $\mathrm{CH}_{3}\left(\mathrm{CH}_{2}\right)_{15}$ $\mathrm{N}\left(\mathrm{CH}_{3}\right)_{3} \mathrm{CrO}_{2} \mathrm{Br}$ could also be recycled after oxidation that means the possibility of re using of this reagent.

CTMABC was very well reagent for the oxidant based on quaternary ammonium halochromates. In our research on oxidation processes, we chose CTMABC as an oxidant; because it was been proven to be a useful oxidant in some reactions including the oxidation of alcohols [23]. CTMABC as an oxidant was a very well suited reagent for microwave synthesis, because as an ionic and magnetically retrievable material, it carries a benefit of efficient conversion of electromagnetic energy into heat according to the dielectric heating mechanism.

The versatility of the procedure was further demonstrated by the oxidation of some natural products such as menthol and the carbohydrate derivatives to corresponding ketones respectively (Scheme 2).

Table 1 summarizes the products, yields and times of reaction of CTMABC with Various alcohols and polyarenes.

The carbonyl compounds were obtained with satisfac tory yield and in a short time $(87 \%-95 \%, 8-23 \mathrm{~min})$ (Table 1) as compare to articles that published earlier by us [23].

The primary alcohols (entry 1a-2a, 7a) were turned into the desired aldehydes without over oxidizing them to carboxylic acids. The reactivity of the secondary alcohols (entry 3a-6a, 8a-9a) seems to be slightly lower, but the addition of higher amount of the oxidant did not increase the yield of desired ketones. It seems that oxidation is also efficient for oxidation of polycyclic arenes such as anthracene and phenanthrene (10a-11a) in microwave irradiation with compare to conventional heating. This

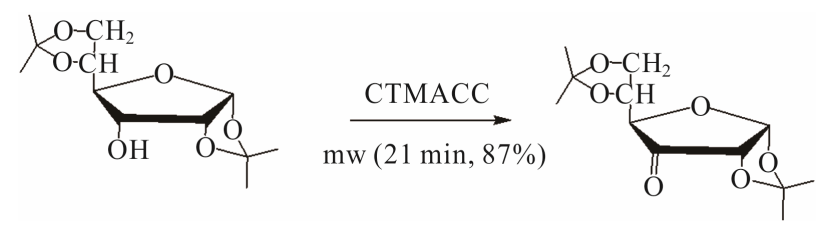

Scheme 2. Oxidation of carbohydrate derivatives with CTMACC. 
Table 1. Oxidation of some organic compounds with CTMABC, under microwave irradiation.

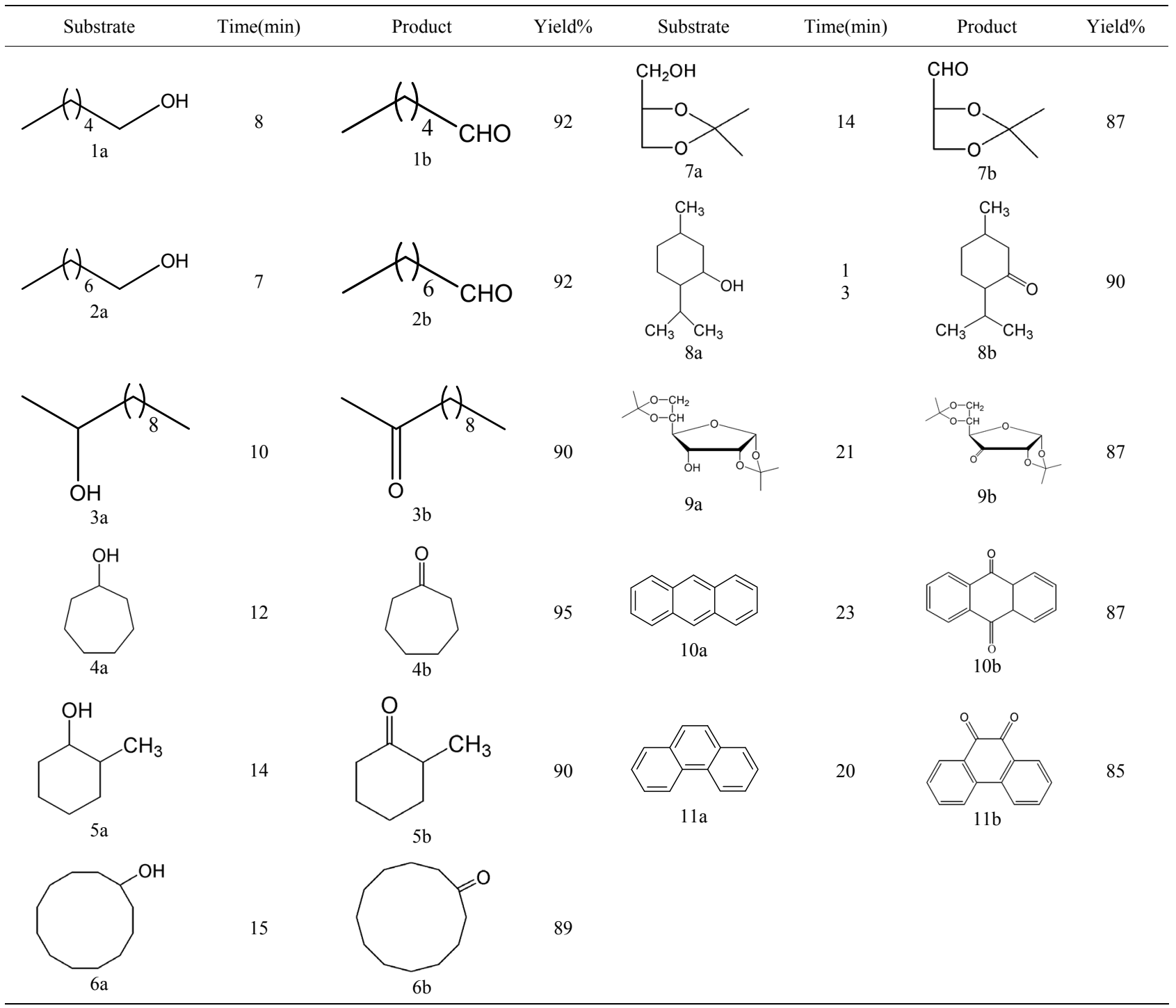

efficiency is best significant in reduction of reaction time as compare to conventional heating method.

\section{Conclusion}

In conclusion, we have described a highly efficient microwave-induced modification of conventional heating procedure for the oxidation of alcohols that allows for the rapid synthesis of aldehydes or ketones. The advantages of this environmentally benign and safe protocol include a simple reaction set-up, application of commercially available quaternary ammonium salts and catalysts, high product yields, short reaction times as well as the elimination of side products.

\section{Acknowledgements}

The author wishes to thank Dr. Sh. Ghammamy, Depart- ment of Chemistry, Imam Khomeini International University, Iran, for many helpful and valuable discussions.

\section{REFERENCES}

[1] B. M. Trost, "Comprehensive Organic Synthesis," Pergamon Press, New York, 1991.

[2] M. Hudlicky, "Oxidations in Organic Chemistry," American Chemical Society, Washington DC, 1990.

[3] K. Sato, M. Aoki and R. Noyori, "A 'Green' Route to Adipic Acid: Direct Oxidation of Cyclohexenes with 30 Percent Hydrogen Peroxide," Science, Vol. 281, No. 5383, 1998, pp. 1646-1647. doi:10.1126/science.281.5383.1646

[4] K. Sato, M. Aoki, J. Tagaki and R. Noyori, "Organic Solvent- and Halide-Free Oxidation of Alcohols with Aqueous Hydrogen Peroxide," Journal of the American Chemical Society, Vol. 119, No. 50, 1997, pp. 1238612387. doi:10.1021/ja973412p 
[5] R. S. Varma and R. K. Saini, "Wet Alumina Supported Chromium(VI) Oxide: Selective Oxidation of Alcohols in Solventless System," Tetrahedron Letters, Vol. 39, No. 12, 1998, pp. 1481-1482. doi:10.1016/S0040-4039(98)00010-0

[6] S. Patel and B. K. Mishra, "Chromium(VI) Oxidants Having Quaternary Ammonium Ions: Studies on Synthetic Applications and Oxidation Kinetics," Tetrahedron, Vol. 63, No. 21, 2007, pp . 4367-4406.

[7] R. S. Varma and R. Dahiya, "Copper(II) Nitrate on Clay (Claycop)-Hydrogen Peroxide: Selective and SolventFree Oxidations Using Microwaves," Tetrahedron Letters, Vol. 39, No. 11, 1998, pp. 1307-1308. doi:10.1016/S0040-4039(97)10763-8

[8] R. S. Varma, R. K. Saini and R. Dahiya, "Active Manganese Dioxide on Silica: Oxidation of Alcohols under Solvent-Free Conditions Using Microwaves," Tetrahedron Letters, Vol. 38, No. 45, 1997, pp. 7823-7824. doi:10.1016/S0040-4039(97)10093-4

[9] R. A. Abramovitch, "Applications of Microwave Energy in Organic Chemistry. A Review," Organic Preparations and Procedures International, Vol. 23, No. 6, 1991, pp. 683-711. doi:10.1080/00304949109458244

[10] J. Azizian, M. K. Mohammadi, O. R. Firuzi, B. Mirza and R. Miri, "Microwave-Assisted Solvent-Free Synthesis of Bis(dihydropyrimidinone)benzenes and Evaluation of their Cytotoxic Activity," Chemical Biology \& Drug Design, Vol. 75, No. 4, 2010, pp. 375-380.

[11] S. Caddick, "Microwave Assisted Organic Reactions," Tetrahedron, Vol. 51, No. 38, 1995, pp. 10403-10432. doi:10.1016/0040-4020(95)00662-R

[12] C. R. Strauss and R. W. Trainor, "Developments in Microwave-Assisted Organic Chemistry," Australian Journal of Chemistry, Vol. 48, No. 10, 1995, pp. 1665-1692. doi:10.1071/CH9951665

[13] D. Bogdal and M. Warzala, "Microwave-Assisted Preparation of Benzo[b]furans under Solventless Phase-Transfer Catalytic Conditions," Tetrahedron, Vol. 56, No. 44, 2000, pp. 8769-8773. doi:10.1016/S0040-4020(00)00818-8

[14] J. A. Seijas, M. P. Vazquez-Tato and J. Crecente-Campo, "Straightforward Microwave-Assisted Synthesis of 2Thiazolines Using Lawesson's Reagent under SolventFree Conditions," Tetrahedron, Vol. 64, No. 39, 2008, pp. 9280-9285.

[15] D. Bogdal, J. Pielichowski and K. Jaskot, "A Rapid Williamson Synthesis under Microwave Irradiation in Dry Medium," Organic Preparations and Procedures International, Vol. 30, No. 4, 1998, pp. 427-432.

\section{doi:10.1080/00304949809355304}

[16] R. S. Varma and R. Dahiya, "The Design and Synthesis of a Conformationally Constrained Trisaccharide for Probing Carbohydrate-Protein Interactions," Tetrahedron Letters, Vol. 38, No. 11, 1997, pp. 2023-2026. doi:10.1016/S0040-4039(97)00223-2

[17] R. S. Varma, R. K. Saini and H. M. Meshram, "Selective Oxidation of Sulfides to Sulfoxides and Sulfones by Microwave Thermolysis on Wet Silica-Supported Sodium Periodate," Tetrahedron Letters, Vol. 38, No. 37, 1997, pp. 6525-6528. doi:10.1016/S0040-4039(97)01520-7

[18] R. S. Varma and R. K. Saini, "Wet Alumina Supported Chromium(VI) Oxide: Selective Oxidation of Alcohols in Solventless System," Tetrahedron Letters, Vol. 39, No. 12, 1998, pp. 1481-1482. doi:10.1016/S0040-4039(98)00010-0

[19] R. S. Varma, K. S. Saini and R. Dahiya, "Active Manganese Dioxide on Silica: Oxidation of Alcohols under Solvent-Free Conditions Using Microwaves," Tetrahedron Letters, Vol. 38, No. 45, 1997, pp. 7823-7824. doi:10.1016/S0040-4039(97)10093-4

[20] R. S. Varma, R. K. Saini and H. M. Meshram, "Selective Oxidation of Sulfides to Sulfoxides and Sulfones by Microwave Thermolysis on Wet Silica-Supported Sodium Periodate," Tetrahedron Letters, Vol. 38, No. 37, 1997, pp. 6525-6528.

[21] K. Bougrin, A. Loupy and M. Soufiaoui, "MicrowaveAssisted Solvent-Free Heterocyclic Synthesis," Journal of Photochemistry and Photobiology C: Photochemistry Reviews, Vol. 6, No. 2-3, 2005, pp. 139-167.

[22] L. Palombi, F. Bonadies and A. Scettri, "MicrowaveAssisted Oxidation of Saturated and Unsaturated Alcohols with T-Butyl Hydroperoxide and Zeolites," Tetrahedron, Vol. 53, No. 46, 1997, pp. 15867-15876. doi:10.1016/S0040-4020(97)10047-3

[23] A. R. Mahjoub, S. Ghammami and M. Z. Kassaee, "Tetramethylammonium Fluorochromate(VI): A New and Efficient Oxidant for Organic Substrates," Tetrahedron Letters, Vol. 44, No. 24, 2003, pp. 4555-4557. doi:10.1016/S0040-4039(03)00989-4

[24] M. N. Bhattacharjee, M. K. Chaudhuri, H. S. Dasgupta and N. Roy, "Pyridinium Fluorochromate; A New and Efficient Oxidant for Organic Substrates," Synthesis, Vol. 1982, No. 7, 1982, pp. 588-590. doi: $10.1055 / \mathrm{s}-1982-29872$

[25] G. Piancatelli, A. Scettri and M. D. Auria, "Pyridinium Chlorochromate: A Versatile Oxidant in Organic Synthesis," Synthesis, Vol. 1982, No. 4, 1982, pp. 245-258. doi: $10.1055 / \mathrm{s}-1982-29766$ 